\title{
Candida colonization in intensive care unit patients' urine
}

\section{Xisto Sena Passos, Werther Souza Sales*, Patrícia Jackeline Maciel*, Carolina Rodrigues Costa*, Karla Carvalho Miranda*, Janine de Aquino Lemos*, Miranildes de Abreu Batista**, Maria do Rosário Rodrigues Silva*/+}

\author{
Universidade Paulista, Goiânia, GO, Brasil *Instituto de Patologia Tropical e Saúde Pública **Faculdade de Medicina, \\ Universidade Federal de Goiás, Rua Delenda Rezende de Melo, 74605-050 Goiânia, GO, Brasil
}

The objective of this study was to identify possible predisposing factors for candiduria in intensive care unit (ICU) patients from Hospital das Clínicas, Universidade Federal de Goiás, Goiânia, Brazil, during one year. Urine samples from 153 ICU patients were obtained by catheterization on admission day and every seven days. Data such as sex, age, antifungal therapy, and variables as antibiotics, underlying diseases or comorbid conditions and stay in the hospital, were collected from patients who had at least one urine culture that yielded $\geq 10^{3}$ yeast colonies $/ \mathrm{ml}$. Candiduria was recovered in 68 patients and the commonest predisposing factors were antibiotic therapy (100\%) and indwelling urinary catheter (92.6\%). The percentage of Candida spp. isolation increased during the extended periods in which patients remained in the ICU. C. albicans was isolated in $69.1 \%$, and the other species non-albicans as C. glabrata, C. kefyr, C. parapsilosis, C. famata, C. guilliermondii, C. krusei, and C. tropicalis were isolated in lower percentage. The high frequency of candiduria and the possible predisposing factors found in ICU patients show that candiduria surveillance should be performed to help reducing nosocomial infections.

Key words: nosocomial infections - predisposing factors - intensive care unit - Candida spp. - Brazil

Although an increase of candiduria among hospitalized patients has been reported, the significance of the presence of yeasts in the urine of patients is not clearly understood (Weber et al. 1992, Nucci 2000). A common clinical problem is to deciding whether candiduria represents urinary tract infections or merely bladder colonization or contamination (Akalm et al. 2004). Distinguishing contamination from true infection is not easy, despite the existence of reliable diagnostic criteria for significant candiduria (Sobel 2002). It has been observed that nosocomial urinary tract infections have increased in the two last decades, probably due to many predisposing factors associated with occurrence of candiduria (Sobel 2002).

Several risk factors such as use of indwelling urinary devices, diabetes mellitus, antibiotic use, immunosuppressive therapy, extended hospitalization, extremes of age and female sex have been identified as associated with increase of Candida growth in urine (Sobel 2002). Although, non-albicans species as $C$. tropicalis and $C$. glabrata have been frequently found in this clinical specimen, C. albicans is still the most frequent yeast recovered from urine cultures (Nucci 2000).

The objective of this study was to identify possible candiduria factors predisposing in intensive care unit (ICU) patients from Hospital das Clínicas, Universidade Federal de Goiás, Goiânia, Brazil, during one year.

Financial support: Universidade Paulista ${ }^{+}$Corresponding author. E-mail: rosario@iptsp.ufg.br Received 2 June 2005

Accepted 6 December 2005

\section{PATIENTS AND METHODS}

Population studied - Urine samples from 153 ICU patients of the Hospital das Clínicas, Universidade Federal de Goiás, state of Goiás, Brazil, were obtained by catheterization in the admission day and every seven days in the ICU. All participants provided informed consent before enrollment and the study was approved by the Ethics Committee of the Hospital das Clínicas. Data such as sex, age, and variables as possible predisposing factors, including antibiotics, underlying diseases or comorbid conditions and stay in the hospital, were collected from patients who had at least one urine culture that yielded $\geq 10^{3}$ yeast colonies/ml.

Culture methods and quantitative culture methods The urine samples were spread by calibrated loop $(0.01 \mathrm{ml})$ onto Sabouraud dextrose agar plates supplemented with $100 \mu \mathrm{g} / \mathrm{ml}$ of chloramphenicol. Plates were incubated aerobically at $37^{\circ} \mathrm{C}$ and read within $24 \mathrm{~h}$. The detection level for quantitative cultures used in this study was $100 \mathrm{CFU} / \mathrm{ml}$, represented by a single colony of yeast on a plate (Koneman et al. 1997). Candida species were identified by germ tube formation in fetal calf serum at $37^{\circ} \mathrm{C}$, colony morphology on cornmeal agar and sugar fermentation and assimilation tests (Kurtzman \& Fell 1998). Identification was confirmed by API 20C Aux System for yeasts (bioMerieux, Marcy L'Etoile, France). C. albicans ATCC 10231 and C. parapsilosis 22019 were included as control.

Statistical methods - All statistical analysis were performed using Statistical Programmer for Social Sciences (SPSS) 11.0 for Windows. The regression linear analysis was used to determine if the time of hospital permanence increased Candida colonization in ICU patients' urine. Chi-square was used to test the correlation of candiduria and women. $\mathrm{P}$ values were significant when $\leq 0.05$. 


\section{RESULTS}

Of the patients studied, 80 were males and 73 were females. The mean age was $53 \pm 19$ years. Among the 153 urine samples cultured, candiduria was recovered in 68 patients. The commonest coexisting exposures in patients with candiduria were antibiotic therapy (100\%) and indwelling urinary catheter $(92.6 \%)$. It was verified that the presence of Candida in the urine was higher in women than in men $(\mathrm{p}=0.001)$. The vast majority of the patients $(80.9 \%)$ had three invasive simultaneously procedures. Underlying conditions as anemia and malnutrition were present in 32.3 and $4.41 \%$ of the patients, respectively (Table I).

\section{TABLE I}

Underlying conditions and risk factors in 68 patients with funguria

\begin{tabular}{lc}
\hline Characteristics & Number $(\%)$ of patients \\
\hline Males & $23(33.8)$ \\
Females & $45(66.2)$ \\
Antibiotic therapy & $68(100)$ \\
Catheter & $63(92.6)$ \\
Probe (drawing urine) & $59(86.8)$ \\
Diabetes mellitus & $5(7.4)$ \\
Anemia & $22(41.2)$ \\
Malnutrition & $3(4.41)$ \\
Parenteral feeding & $51(75)$ \\
Use of three invasive procedures & $55(80.9)$ \\
\hline
\end{tabular}

The ICU permanence as possible predisposing factor for development of funguria was analyzed separately. It was verified that urine culture was positive in 43 patients in the admission day and in 25 patients the detection of yeasts occurred in 8 to 42 days (mean $10.4 \pm 12.3$ ) of hospital permanence. Candiduria persisted in 21 patients. In 45 patients new urine sample were not collected because of death ( 24 patients) or transfer to another extended care facility (21 patients). The predominant species were $C$. albicans, isolated from urine of $69.1 \%$ of the patients (47/
68), followed by C. glabrata, isolated in 7.4\% (5/68). This later species was isolated in four women $(80 \%)$.

During the period under study, 25 patients developed candiduria in the ICU. The percentage of Candida sp., isolation increased during the extended period in which patients remained in the ICU. We observed a linear trend towards increasing numbers of Candida positive cultures; this increase was statistically significant $(\mathrm{p}=0.001)$. Data about candiduria etiology at hospital admission and every 7 days are shown in Table II.

\section{DISCUSSION}

Fungal nosocomial infection has become an important problem on the past decade (Oravcova et al. 1996). In the present study, candiduria was detected in $44.4 \%$ (68/ 153) of the ICU patients. This high incidence of funguria in this unit should be considered very important. According to some authors, presence of funguria in those patients might be indicative of urinary tract or systemic infection (Nassoura et al. 1993).

Although $C$. albicans has been the commonest etiologic agent, non-albicans species were isolated in 31.9\% of the urine samples. The emergence of non-albicans species may represent selection of less susceptible species by antifungal agents as fluconazole in particular. Some Candida strains as C. glabrata and C. krusei are less susceptible to fluconazole than C. albicans (Morace et al. 1991, Hoppe et al. 1994, Nenoff et al. 1999). Similar results about emerging species occurrence have been observed in hospitalized patients (Rezende et al. 2002).

Many risk factors may favor or contribute to patient colonization. Some investigators have showed that use of antibiotics, presence of central venous catheter, and prolonged hospital permanence represent important risk factors for the development of microorganisms (Kauffman et al. 2000, Blumberg et al. 2001, Simpson et al. 2004). We verified in our work that all patients were under antibiotic use $(100 \%)$. These drugs play a critical role in the pathogenesis of candiduria, which emerges during antibiotic therapy or immediately after it. By suppressing susceptible endogenous bacterial flora in the gastrointestinal and lower genital tracts, antibiotic favors epithelial sur-

\section{TABLE II}

Data on the etiology of candiduria in the admission day and after every seven days during intensive care unit stay of the Hospital das Clínicas, Universidade Federal de Goiás, Brazil

\begin{tabular}{|c|c|c|c|c|c|c|}
\hline Yeasts & $\begin{array}{c}\text { Positive } \\
\text { cultures } \\
\text { at admission } \\
\text { day }\end{array}$ & $\begin{array}{l}\text { Cultures that } \\
\text { become positive } \\
\text { after the first } \\
\text { culture }\end{array}$ & $\begin{array}{l}\text { Patients that } \\
\text { became negative } \\
\text { after the first } \\
\text { culture }\end{array}$ & $\begin{array}{l}\text { Patients } \\
\text { that have } \\
\text { remained } \\
\text { positive }\end{array}$ & $\begin{array}{c}\text { Obit } \\
\text { before } \\
\text { second } \\
\text { culture }\end{array}$ & $\begin{array}{l}\text { Discharge } \\
\text { before } \\
\text { second } \\
\text { culture }\end{array}$ \\
\hline Candida albicans & 30 & 17 & 1 & 18 & 14 & 14 \\
\hline C. glabrata & 3 & 2 & - & - & 4 & 1 \\
\hline C. kefyr & 2 & 1 & - & 1 & 1 & 1 \\
\hline C. parapsilosis & 2 & 2 & - & 1 & - & 3 \\
\hline C. famata & 3 & - & - & 1 & 2 & - \\
\hline C. guilliermondii & - & 2 & - & - & 2 & - \\
\hline C. krusei & 1 & 1 & 1 & - & 1 & - \\
\hline C. tropicalis & 2 & - & - & - & - & 2 \\
\hline Total & 43 & 25 & 2 & 21 & 24 & 21 \\
\hline
\end{tabular}


face fungal colonization, with ready access to the urinary tract, specially in the presence of indwelling bladder catheter (Fisher et al. 1982, Sobel \& Vazquez 1999).

This study showed that in most cases of candiduria the patient had a urinary catheter $(92.6 \%)$. Similar results have been obtained by Kobayashi et al. (2004), who verified that $84.4 \%$ of the patients with candiduria had a catheter. According to Klotz and Smith (1990), yeasts are able to adhere to the catheter, allowing colonization in this device. Although infection by yeasts in patients with indwelling urinary catheter has not been well defined till now, use of invasive procedures has been reported as an important factor for development of Candida spp. infection (Álvarez-Lerma et al. 2003).

Interestingly, candiduria was higher in females $(61.6 \%)$ than in males $(\mathrm{p}=0.001)$. This incidence in females may reflect vaginal candidiasis. Yeasts may ascend from the genital tract to the urinary tract, explaining a higher candiduria incidence in women. This hypothesis was suggested by Febré et al. (1999), who found five of eight patients with positive vaginal secretions and later showed the presence of the same yeast species in their urine. $C$. glabrata, described as etiologic agent of vaginal candidiasis in several cases (Del Palacio et al. 2000), was recovered in our study in five patients, among whom four were women.

Consistent with the observations of other investigators (Ahmad et al. 2003, Álvarez-Lerma et al. 2003), we found that patients with ICU stay > 1 week had higher urine Candida colonization than in the admission day. According to some researchers most of the probable sources of nosocomial acquisition in ICU appear to be originated endogenously, but there is also evidence that exogenous infection or cross-infection from nursing staff may occur (Ahmad et al. 2003, Khan et al. 2003). It is evident that the risk factors should be considered for acquisition of Candida in urine. The acquisition source was not investigated in our study.

Although previous studies indicate that asymptomatic candiduria is usually benign, even in debilitated patients, and eradication of funguria without use of specific antifungal agents has been verified, candiduria should never be ignored, since this condition may be the only (and is often the first) indication of systemic or invasive candidiasis (Sobel 1999). Ahmad et al. (2003) observed that two $C$. albicans isolates from candidemia patients were similar to those from their urine and oral isolates, analyzed by random amplification of polymorphic DNA, reinforcing the point of view that prior colonization is a risk factor. Then, candiduria surveillance should be performed to help reducing nosocomial infections. In conclusion, in our study we verified a high frequency of candiduria in patients from ICU, and the permanence in hospital was an important factor for acquisition of Candida.

\section{REFERENCES}

Ahmad S, Khan Z, Mustafa SA, Khan ZU 2003. Epidemiology of Candida colonization in an intensive care unit of a teaching hospital in Kuwait. Med Mycol 41: 487-493.

Akalm H, Ener B, Kahveci F, Akçaglar S, Gürcan S, Töre O
2004. Persistent of candiduria in ICU catherized patients is not linked to adherence and proteolytic activities of Candida strains. Intens Care Med 30: 972-975.

Álvarez-Lerma F, Nolla-Sallas J, Palomar M, Jordá R, Carrasco N, Bobillo F 2003. Candiduria in critically ill patients admitted to intensive care medical units. Inten Care Med 29: 1069-1076.

Blumberg HM, Jarvis WR, Soucie JM 2001. Risk factors for candidal bloodstream infections in surgical intensive care unit patients: the NEMIS prospective multicenter study. The National Epidemiology of Mycosis Survey. Clin Infect Dis 33: 177-186.

Del Palacio A, Sanz F, Sánchez-Alor G, Garau M, Calvo MT, Boncompte E, Algueró M, Pontes C, de la Cámara AG 2000. Double-blind randomized dose-finding study in acute vulvovaginal candidosis. Comparison of flutrimazole sitereleaseB cream (1, 2 and 4\%) with placebo site-releaseB vaginal cream. Mycoses 43: 355-365.

Febré N, Silva V, Medeiros EAS, Wey SB, Colombo AL, Fischman O 1999. Microbiological characteristics of yeasts isolated from urinary tracts of intensive care unit patients undergoing urinary catherization. J Clin Microbiol 37: 15841586.

Fisher JF, Chew WH, Shadomy S, Duma RJ, Mayhall CG, House WC 1982. Urinary tract infection due to Candida albicans. Rev Infect Dis 4: 1107.

Hoppe JF, Klingebiel T, Niethammer D 1994. Selection of Candida glabrata in pediatric bone marrow transplant in patients receiving fluconazole. Pediatr Hematol Oncol 11: 207210.

Kauffman CA, Vazquez JA, Sobel JD, Gallis HA, McKinsey DS, Karchmer AW, Sugar AM, Sharkey PK, Wise GJ, Mangi R, Mosher A, Lee JY, Dismukes WE 2000. Prospective multicenter surveillance study of funguria in hospitalized. Clin Infec Dis 30: 14-18.

Khan ZU, Chandy R, Metwali KE 2003. Candida albicans strain carriage in patients and nursing staff of an intensive care unit: a study of morphotypes and resistotypes. Mycoses 46: 479-486.

Klotz J, Smith RL 1990. Gelatin fragments inhibit Candida albicans yeast adherence to ECM. Annual Meeting American Society of Microbiology, $100 \mathrm{pp}$.

Kobayashi CCBA, Fernandes OFL, Miranda KC, Souza ED, Silva MRR 2004. Candiduria in hospital patients: A study prospective. Mycopathologia 158: 49-52.

Koneman EW, Allen SC, Dowell VR, Janda WM, Sommers HM, Winn WC 1997. Diagnóstico Microbiológico: Texto y Atlas Color, 3rd ed., Editorial Médica Panamericana, México, p. 139-140.

Kurtzman CP, Fell JW 1998. The Yeasts, a Taxonomic Study, 4th ed., Elsevier, New York, p. 891-947.

Morace G, Manzara S, Dettori G 1991. In vitro susceptibility of 119 yeasts isolates to fluconazole, 5-fluorocytosine, amphotericin B and ketoconazole. Chemotherapy 37: 2331.

Nassoura Z, Ivatury RR, Simon RJ, Jabbour N, Stahl WM 1993. Candiduria as an early marker of disseminated infection in critically ill surgical patients: the role of fluconazole therapy. J Trauma 35: 290-5. 
Nenoff P, Oswald U, Haustein F 1999. In vitro susceptibility of yeasts for fluconazole and itraconazole. Evaluation of a microdilution test. Mycoses 42: 629-639.

Nucci M 2000. Candiduria in hospitalized patients: A review. Bras J Infec Dis 4: 168-172.

Oravcova E, Lacka J, Drgona L 1996. Funguria in cancer patients: analysis of risk factors, clinical presentation and outcome in 50 patients. Infection 24: 319-23.

Rezende JCP, Rezende MA, Saliba JL 2002. Prevalence of Candida spp. in hospitalized patients and their risk factors. Mycoses 45: 306-312.
Simpson C, Blitz S, Shafran SD 2004. The effect of current management funguria. J Infection 49: 248-252.

Sobel JD 1999. Management of asymptomatic candiduria. Int $J$ Ant Agents 11: 285-288.

Sobel JD 2002. Controversies in the diagnosis of candiduria: What is the critical colony count? Infect Dis 4: 81-83.

Sobel JD, Vazquez JA 1999. Fungal infection of the urinary tract. World J Urol 17: 410-414.

Weber DJ, Rutala WA, Samsa GP 1992. Relative frequency of nosocomial pathogens at a university hospital during the decade 1980 to 1989. Am Infect Control 20: 192-197. 